В последние 4 года снизили затраты на социальные издержки на проведение социальных программ и т.д. Государство начало уделять мало средств из бюджета, что в дальнейшем сыграло свои последствия. Но как же наладить положение в стране? К вашему вниманию мы хотим предложить отличное решение данной проблемы - инжиниринговые центры на базе данных социальной инженерии, ВУЗов и научных центров, т.е. финансировать перспективные направления науки, выделять гранты, субсидировать научные проекты. Ведь среди студентов, научных работников можно встретить очень талантливых людей, которые своими идеями могут помочь нашей стране в развитии разных отраслей хозяйства. Но для этого нужно спонсировать и помогать специалистам для реализации их планов. Проанализировав ситуацию, необходимо отметить, что Правительство Российской Федерации утвердило Правила предоставления грантов в форме субсидий из федерального бюджета на реализацию проектов по созданию и развитию инжиниринговых центров на базе образовательных организаций высшего образования и научных организаций Постановлением № 1156 от 1 августа 2020 года [2].

В результате проведённого нами исследования можно сделать следующие выводы: сокращение и снижение финансирования исследований в области иммунологии и вирусологии, которое происходит в период переходной экономики, вызвали необратимые изменения в структуре социальных издержек. Недостаточное внимание к социальному сектору привело к серьёзным последствиям, которые произошли в России в период пандемии. Это наглядный предмет, пусть и очень тяжелый, который уже заставил Правительство пересмотреть свои познания в сфере социальной политики (здравоохранения, образования).

Мы рекомендуем формирование инжиниринговых центров на базе социальной инженерии, которые должны реализовать поставленные задачи перед государством по сокращению социальных издержек, через эффективное использование трех составляющих: социальной, экономической и технологической. На основании Постановления Правительства государство планирует финансировать гранты, выделять субсидии на научные разработки и проекты в различных областях, медицины, приборостроения, IT-технологии и других важных отраслей. Надеемся, что представленные рекомендации будут реализованы!

$$
* * *
$$

1. Дайджест. Транспортная сфера в контексте COVID-19 // Счётная палата Российской Федерации, 2020 - 53 с.

2. Постановление Правительства Российской Федерации № 1156 от 1 августа 2020 года: http://publication.pravo.gov.ru/Document/View/0001202008060011

\title{
Пидяшова А.А., Маркосян О.P. \\ К вопросу о феномене денежных ставок на тотализаторе (на исход спортивных событий)
}

Краснодарский филиал РЭУ им. Г.В. Плеханова

doi: 10.18411/trnio-09-2021-26

(Россия, Краснодар)

\section{Аннотация}

В данной работе отражено исследование, в ходе которого было раскрыто понятие ставок на спорт, определены стратегии и перспективы ставок. Целью данного исследования является анализ деятельности букмекерских контор и изучение механизма ставок. Для этого было изучено множество источников и букмекеров, а также было взято во внимание мнение людей, которые занимаются данным видом деятельности.

Ключевые слова: ставки, спорт, букмекерские конторы, коэффициенты, выигрыш. 


\section{Abstract}

This paper reflects a study, during which the concept of sports betting was revealed, strategies and betting prospects were determined. The purpose of this study is to analyze the activities of bookmakers and study the mechanism of bets. For this, many sources and bookmakers were studied, and the opinions of people who are engaged in this type of activity were taken into account.

Keywords: bets, sports, bookmakers, odds, winnings.

Результаты исследования и их обсуждение. В последнее время все большее распространение получают заработки за счет ставок на спорт. Этот факт определяется тем, что во - первых, ставки на спорт не являются запрещенным видом деятельности в Российской Федерации; во - вторых, в век технологий букмекеры просачиваются в интернет, где и получают свое распространение.

Любители спорта достаточно часто могут предугадывать исход спортивных соревнований. В связи с этим и образовались букмекерские конторы, которые предлагают монетизировать удачу и знания в области спорта. Плюс, многие игроки отмечают, что делая ставки, намного интереснее наблюдать за исходом событий, поскольку появляется азарт получить крупную сумму денег.

Перед началом исследования следует установить, что процесс ставок называется «беттингом», а игроки «беттерами».

Многие люди, которые скептически относятся к ставкам на спорт, говорят о том, что ставки - прямой путь к банкротству. Так ли это на самом деле? Однозначно ответить на этот вопрос нельзя, поскольку никто не заставляет «беттеров» вкладывать огромные суммы денег. Конечно, если человек психически не здоров и чрезвычайно азартен, то есть риск того, что он не сможет остановиться на какой то определенной сумме, которая в случае потери, не повлияет на его уровень жизни. Опытные игроки ежемесячно выделяют конкретную сумму из своего бюджета, которая откладывается для ставок на спорт. То есть они разграничивают деньги на жизнь и на ставки.

Что же нужно для того, чтобы начать зарабатывать на ставках? Для старта необходимо следующее:

- $\quad$ знания и интерес к какому - либо виду спорта;

- $\quad$ свободные денежные средства (банкролл);

- $\quad$ доступ к интернету (если ставки делаются через интернет);

- $\quad$ стабильная психика и умеренный азарт.

Опытные беттеры расценивают заработок со ставок на спорт, как работу. Поэтому они ежедневно тратят по нескольку часов для сбора и анализа информации, разработки и реализации стратегий.

Важным аспектом в ставках является трезвый ум, который не дает эмоциям взять верх. Естественно, у каждого любителя спорта есть своя любимая команда, однако, не стоит слепо верить в ее победу. Всегда нужно досконально изучать все нюансы игры и соперников. Также не стоит делать ставки на команду по чьим-то советам.

Одной из главных ошибок новичков является то, что они в случае проигрыша пытаются сразу же сделать новые ставки, чтобы отыграться. Этого делать категорически нельзя. В момент проигрыша, человека переполняют эмоции, а ставки, как мы уже выяснили, не терпят эмоций. Лучше всего подождать пару часов или дней, чтобы разобрать свои ошибки. А уже затем, с холодной головой, делать новые ставки.

Для того, чтобы разобраться в механизме работы ставок на спорт, рассмотрим их виды. Ставки бывают трех основных видов: одиночные, групповые и множественные. Рассмотрим каждый вид в отдельности.

- $\quad$ Одиночные ставки. 
Они считаются самыми простыми и идеально подходят для новичков. Суть данного вида ставок заключается в том, что игрок выбирает одно событие, на которое и делает ставку. Если беттер угадывает, то получает свой выигрыш: ставку, умноженную на коэффициент. В случае проигрыша все деньги остаются у букмекеров.

В свою очередь одиночные ставки подразделяются на ряд разновидностей:

$\checkmark \quad$ ординар - ставка на единственный исход события;

$\checkmark$ двойной шанс - ставка на 2 из 3-х возможных событий;

$\checkmark \quad$ фора - ставка на разницу в счете;

$\checkmark$ тотал - ставка на суммарное количество очков;

$\checkmark \quad$ тайм-матч - ставка на исход одного тайма или всего матча в целом.

- $\quad$ Групповые ставки.

Данный вид ставок уже сложнее и основан он на том, что игрок выбирает несколько событий, а не одно. Как правило, групповые ставки делают во время крупных чемпионатов. Эти ставки классифицируют на еще 2 вида:

$\checkmark \quad$ экспресс - ставка, когда игрок ставит на несколько событий. В случае выигрыша все коэффициенты по событиям и ставка перемножаются. Однако, в случае, если игрок ошибся хотя бы в одном событии, ставка остается у букмекера;

$\checkmark \quad$ система - это несколько экспресс-ставок, каждая из которых включает в себя одинаковое количество событий. Если игрок проигрывает по какому- то событию в одной экспресс-ставке, то проигрывает только эта ставка. В системе еще остается шанс на выигрыш.

- Множественные.

Данный вид ставок представляет собой различные сочетания одиночных и групповых ставок. Их существует огромное множество, среди которых выделяют самые популярные:

$\checkmark$ trixie - выбирается 3 события и делается 4 ставки. Например, есть события A,B и С. По этим событиям делаются следующие ставки: «Экспресс 1»A,B; «Экспрес 2» - В,С; «Экспресс 3»- А,C; «Экспресс 4» - A,В,C;

$\checkmark$ patent - делается 7 ставок. 4 ставки «Trixie» и 3 одиночные ставки на каждое событие;

$\checkmark \quad$ yankee - делается 11 ставок из 4 событий: 6 двойных экспрессов, 4 тройных и один - на 4 события сразу.

Если игрок, сделав несколько ставок, понимает, что хочет и дальше продолжать этим заниматься, то ему необходима разработка стратегии. Беттеры подразделяют все стратегии на 3 категории: долгосрочные, предматчевые и live. Рассмотрим их в отдельности.

Долгосрочные стратегии основаны на статистических данных. Эти ставки делаются за несколько недель до начала матча.

Предматчевые ставки основаны на текущих данных и делаются непосредственно перед началом события.

Live ставки делаются во время матча.

Для новичков, конечно же, рекомендуется долгосрочная стратегия, которая дает возможность долго анализировать и обдумывать ход игры. Live ставки больше подходят для опытных беттеров, поскольку здесь важна быстрая реакция на ход событий, которая приходит с опытом.

Для многих остается открытым вопрос: можно ли разбогатеть на ставках? Лэм Бэнкер доказал своим опытом, что это вполне возможно.

Лэм Бэнкер ни дня в своей жизни не ходил на обычную работу. Его умению управлять банкроллом может позавидовать любой опытный беттер. Ставками на спорт он заработал на огромный особняк в Лас - Вегасе, а шикарные автомобили меняет в зависимости от настроения. Любовь к ставкам у Лэма передалась по наследству. Дело в том, что у его отца была собственная кондитерская, в которой посетители могли подпольно сделать ставки на спорт. 
В юности Лэм Бэнкер учился в колледже и за счет больших успехов в баскетболе ему начисляли стипендию. Эти деньги молодой Лэм тратил на свою главную слабость - ставки. Он пошел по стопам отца и принимал у студентов колледжа подпольные ставки. Далее он нелегально открыл свою букмекерскую компанию. В то время в Нью -Джерси ставки были запрещены и Лэму приходилось постоянно подкупать полицию. Устав от нелегальных ставок он начал задумываться о переезде. В 30 лет ему удалось переехать в Лас - Вегас, где ставки были разрешены. В кармане у него было 1500 долларов и он начал активно заниматься ставками на спорт. К 1960-м годам у Лэма в сбережениях уже было около 10000 долларов и влиятельные связи. Залог его успеха заключался в том, что беттер тратил очень много времени на поиск контор с хорошими коэффициентами. Также очень важным фактором является то, что у Лэма было множество помощников, которые узнавали все новости спорта. В то время это было очень важно, поскольку без интернета узнавать все спортивные новости было очень сложно.

Как же ставил Лэм Бэнкер? В 90-х годах он делал около 100 ставок в неделю и если $60 \%$ ставок выигрывали, он признавал, что за эту неделю сумел озолотиться. Сумма каждой ставки, по мнению Лэма, не должна превышать 3\% от всего банкролла, а увеличивать размер ставки необходимо только тогда, когда выигрываешь и увеличиваешь свой банкролл.

Сейчас Лэму Бэнкеру 92 года и он до сих пор занимается ставками на спорт, хотя с его сбережениями в этом нет необходимости.

Данный пример, конечно, является очень мотивирующим. Однако, есть и более плачевные примеры.

Евгений Кузьмин- человек, который в нужный момент не смог взять себя в руки и вовремя «завязать» со ставками на спорт. Это привело к разрушению семьи, карьеры, кредитам и многочисленным долгам.

Его история начинается с того, что он решил за компанию с другом поставить деньги на одну футбольную команду. Евгению не хватало денег на квартиру и он решил, что ставки помогут ему в накоплениях. Первая его ставка - 10000 рублей, а коэффициент выигрыша составлял 3,8 . Команда, на которую поставил юный беттер одержала победу, и Евгений выиграл 38000 рублей. Воодушевленный, он решил на следующий день сделать еще одну ставку и опять выиграл. В этот момент и началась его зависимость от ставок.

Через некоторое время в России начали появляться первые букмекерские конторы на просторах интернета. Это еще больше затянуло Евгения, поскольку для того, чтобы делать ставки, не надо никуда ехать. Он делал уже не одну ставку в неделю, а несколько ставок в день.

Чуть позже Евгений женился и «завязал» со ставками. Но через год болезнь вернулась снова, и беттер начал играть уже на семейные сбережения. Жена по началу не догадывалась о тайной страсти своего мужа, а когда все-таки узнала правду, ставки были поводом для многочисленных ссор.

Последней точкой был проигрыш 100000 рублей. Жена, осознав, что Евгений крайне азартный человек, который не может вовремя остановиться, подала на развод.

В состоянии эмоциональной подавленности и алкогольного опьянения, беттер разом проиграл все свои сбережения. На утро, осознав, что произошло, Евгений решил больше никогда не делать ставок на спорт.

На самом деле, пример таких судеб, как у Евгения Кузьмина, далеко не единственный. Многие беттеры, также как и наш герой, начинают свою деятельность в ставках «за компанию». И самая ужасная ошибка, которую они допускают - отсутствие дифференциации доходов на жизнь и на ставки. Поэтому, особо азартные по своей натуре люди, проигрывают квартиры, машины, берут кредиты, долги и т.д.

А теперь рассмотрим деятельность конкретной букмекерской конторы. Многие наслышаны о такой конторе, как 1XBET. Ее реклама заполонила весь интернет. Многие блогеры и знаменитости рекомендуют делать ставки именно там, также перед просмотром практически каждого фильма или сериала высвечивается реклама 1XBET. Так что, наверно, 
и не осталось ни одного пользователя интернета, который не знал бы про эту букмекерскую контору. Именно поэтому мы решили проанализировать ее деятельность.

Уже очень давно на просторах интернета существует букмекерская компания 1XBET. Она находится в черном списке во многих странах. Доменные имена сайта постоянно блокируются. Контора даже на главной странице сайта просит беттеров ввести свой номер телефона, чтобы они могли присылать игрокам новые ссылки. Также стоит отметить, что $1 \mathrm{XBET} \mathrm{имеет} \mathrm{самый} \mathrm{низкий} \mathrm{рейтинг} \mathrm{на} \mathrm{сайте} \mathrm{букмекеров.}$

Почему так происходит? 1ХВЕТ зачастую блокирует счета своих игроков, когда те начинают выходить в плюс. Компания обосновывает это тем, что счета замораживаются для проверки каких-то данных.

Через некоторое время на просторах интернета появляется букмекерская контора 1 ХСтавка, которая получает официальную лицензию букмекерской конторы Российской Федерации. И эта контора начинает одну из самых глобальных рекламных компаний. Они начинают покупать рекламу у многих крупных блогеров. Однако, тут есть одна интересная зацепка. В техническом задании, которое выдает букмекер блогерам, прописано название компании не 1ХСтавка, а всеми известный 1ХВЕТ. Однако, ссылка, которую оставляют блогеры, переправляет нас на сайт 1 ХСтавка. То есть, 1 ХВЕТ и 1 ХСтавка - это одна и та же компания.

Однако, занимательным является тот факт, что если 1 XВET находится в черном списке, то 1ХСтавка, чуть ли ни является лидером среди букмекеров. Происходит это, вопервых, из -за того, что 1 ХСтавка - сравнительно новая платформа; во - вторых, по мнению многих IT-экспертов, компания покупает хорошие комментарии и накручивает положительные оценки.

Однако, в отличии от 1XBET, 1ХСтавка имеет лицензию, которая обеспечивает законную деятельность конторы на территории Российской Федерации. То есть, в противном случае, когда беттер не сможет вывести деньги, он может обратиться в суд и через него получить свои деньги. Однако, это не совсем так.

Конечно, лицензия у компании действительно имеется. Более того, их контролирует организация ЦУПИС. ЦУПИС - это кредитная организация, заключившая договор с саморегулируемой организацией букмекеров. Она выполняет роль посредника между игроком и букмекерской компанией, осуществляя учет денежных операций между сторонами. То есть, игрок делает ставку и сумма ставки отправляется не букмекеру, а в ЦУПИС. В таком случае, если ставка сыграла, то игрок гарантированно получает свой выигрыш, если же беттер проиграл, то сумма ставки отправляется букмекеру. Таким образом, беттер защищен он мошенничества букмекеров.

Однако, букмекерская контора 1ХСтавка оказалась более хитрой. По логике этой компании, если выигрыш у игрока нельзя забрать просто так, то их можно проиграть за него.

У компании есть все данные для входа в аккаунт игрока, чем, собственно, она и пользуется. То есть букмекер с профиля беттера делает ставки, чтобы проиграть выигранную сумму.

То есть в данном случае, ни техническая поддержка, ни ЦУПИС, ни какие - либо другие компетентные органы не могут доказать акт мошенничества, поскольку ставки совершались с личного аккаунта игрока.

Также 1ХСтавка обманывает беттеров путем изменения ставок во время игры. То есть, когда букмекер видит, что ставка с большим коэффициентом начинает выигрывать, они во время игры меняют ставку на более низкую, чтобы не выплачивать крупный выигрыш. На вопросы игроков, компания отвечает, что изначально в системе был сбой и коэффициент, который высвечивался ранее, неправильный.

Делая вывод о деятельности 1ХВЕТ или 1ХСтавка, можно с уверенностью сказать, что данные конторы являются мошенниками, которые любой ценой не дадут игроку вывести свой выигрыш. 
Как раз из -за таких мошенников многие люди боятся делать ставки, поскольку не хотят напороться на мошенников. Однако, если хорошо разобраться в деятельности каждой компании, можно с легкостью понять, какая компания является действительно букмекерской конторой, а какая скрывает мошенническую деятельность, прикрываясь ставками на спорт.

Мы же считаем, что делать ставки на спорт лучше в реальных букмекерских конторах, а не в интернете. Поскольку, во-первых, в интернете намного чаще встречаются мошенники, выдающие себя за букмекерскую контору. Во-вторых, пример Евгения Кузьмина показывает, что чем проще делать ставки, тем больше азарта появляется и хочется больше играть. А в случае, когда для того, чтобы сделать ставку нужно сначала куда то поехать, человек на психологическом уровне несколько раз подумает, прежде чем поехать в букмекерскую контору.

И все же, как заработать на ставках? Что необходимо знать для получения прибыли и какие ошибки не стоит совершать?

Самое главное, как уже отмечалось ранее, необходимо иметь банкролл, чтобы не проиграть все свои сбережения и не остаться на улице. Величина банкролла определяется индивидуально, в зависимости от того, какая сумма денег не считается для вас критичной.

Далее необходимо выбрать букмекерскую контору. Букмекерская контора также определяется индивидуально, в зависимости от того, что для вас важно: коэффициенты, бонусы, имидж конторы и т.д. Не стоит торопиться с выбором букмекерской компании. Нужно досконально изучить все возможные варианты и выбрать наиболее подходящий.

Следующий важный пункт в заработке по средствам ставок- это управление банкроллом. Нецелесообразно ставить все деньги на одну ставку. Куда лучше разделить банкролл на 10-20 частей и ставить эти суммы на разные исходы.

После того, как были сделаны все эти пункты, переходим к выбору и анализу событий. В этом пункте главным смыслом является то, что никогда нельзя никого слушайте, кроме себя. Ни для кого не секрет, что большое количество популярных блогеров рекламируют не только определенную букмекерскую контору, но и исход, на который нужно поставить для выигрыша. Ни в коем случае нельзя на это вестись, поскольку данная информация, ни что иное как коммерческий ход, который принесет прибыль и букмекерской конторе и блогеру, но никак не беттеру.

Для того, чтобы правильно выбрать событие, необходимо подвергать его критическому анализу. На это может быть затрачено очень много времени, поскольку все нюансы должны быть сверены и проанализированы. От того, насколько хорошо беттер анализирует информацию, связанную с событием, напрямую зависит его успех. При чем для поиска информации не нужны какие либо закрытые источники или дополнительные затраты. В век технологий, вся необходимая для беттера информация находится в общем доступе в Интернете.

Следующим пунктом стоит выделить азарт. Что имеется в виду? Имеется в виду то, что в ставках необходимо должным образом дисциплинировать в себе азарт. Опытные беттеры отмечают, что чувство азарта появляется от того, что у беттера нет цели к чему то прийти. Управление азартом напрямую зависит от того, есть ли у беттера четкий план, банкролл, анализирует ли он события перед ставками и т.д. В этом случае беттер уже знает как действовать и меньше переживает за исход событий. Если же наоборот, у беттера нет банкролла или он не умеет им грамотно распоряжается, если у него нет определенного плана или он не настроен критически анализировать события, то в таком случае человек впадает в панику, а в последствии эта паника преобразуется в азарт. В свою очередь, азарт приводит людей к ужасному состоянию - к зависимости и «болезни» ставками.

Еще одним пунктом опытные беттеры выделяют то, что не стоит рассматривать ставки как основной вид заработка. К данному виду деятельности стоит относиться как к хобби. Во-первых, если беттер имеет работу, то у него есть финансовая подушка безопасности. Во-вторых, если у беттера нет работы, то у него появляется большое количество свободного времени, которое он тратит на постоянный мониторинг событий, что 
может привести к состоянию одержимости. Важно отметить, что большое количество времени проведенное за поиском информации не всегда хорошо сказывается на ставках, поэтому везде нужно придерживаться правила «золотой середины» и не впадать из крайности в крайность.

Тем не менее в истории ставок на спорт есть очень интересные и сумасшедшие выигрыши, речь о которых пойдет сейчас.

В 2010 году в первом тайме кубка африканских наций в матче между Анголой и Мали, на 78 минуте Ангола выигрывала со счетом 4:0. Тем не менее один из болельщиков, имя которого осталось неизвестным, поставил 5 фунтов на ничью. На этот исход букмекеры ставили коэффициент 1000 к 1. В течение 15 минут команда Мали забила 4 гола, что принесло беттеру выиграш в размере 5000 фунтов или 8000 долларов США.

Сборная Германии устроила бразильцам настоящий разгром в полуфинале чемпионата мира 2014 года. Это поражение стало для Бразилии самым крупным за всю историю существования национальной сборной. Как ни странно, но этот матч принес деньги сразу нескольким игрокам букмекерских контор, которые поставили на счет 1:7 в пользу немецкой сборной. Но самый большой куш на этом матче сорвал один из болельщиков Германии. Беттер не только угадал счет, но и указал автора одного из голов. В итоге 20 долларов беттера были умножены на коэффициент 1319, что принесло ему свыше 40000 долларов США чистого дохода.

Один из болельщиков Ливерпуля поставил 200 фунтов на то, что один из игроков его любимой команды до конца сезона забьет гол с центра поля. Букмекеры давали на это событие коэффициент 125. Позднее болельщик признался, что такой гол ему просто на просто приснился и он решил, что это вещий сон. И этот сон сбылся. Он принес ему выручку около 50000 долларов США.

В 2008 году белорусский прогнозист сумел угадать в своем экспрессе исходы сразу 14 матчей. Ставку он сделал на игры сборных в отборе чемпионата мира 2010 года. Общий коэффициент в его невероятном экспрессе получился почти 210000 . Но, к сожалению, он поставил только 50 центов, поэтому выигрыш составил лишь 105000долларов США.

В букмекерском мире можно делать ставки практически на все, что угодно. Даже на то, каких профессиональных высот добьются твои дети или внуки. Так сделал дедушка двухлетнего Харри Уилсона поставив на то, что его внук когда-нибудь сыграет за национальную сборную Уэльса. В итоге ставка в 50 фунтов на коэффициент 2500 к 1 , принесла дедушке 180000 долларов США. Ведь 15 октября 2013 года в возрасте 16 лет Харри Уилсон вышел на замену в матче против Бельгии.

Мало кто верил в Грецию на чемпионате Европы в 2004 году. Но один болельщик верил в команду несмотря ни на что и уже в начале турнира поставил на победу Греции 7300 долларов с коэффициентом 50. По ходу соревнований, видя успехи своей сборной, он поставил еще 14600 долларов на тот же исход, но уже с коэффициентом 10. Перед самим финалом он поставил на победу Греции еще раз 22860 долларов с коэффициентом 4,2. В итоге финальный матч Евро принес болельщику суммарный выигрыш в размере 607000 долларов США.

В ноябре 2017 года 58-летняя британка выиграла с 1 фунта свыше полмиллиона. При этом, свой экспресс с 12 событиями она поставила совершенно случайно. По словам женщины от футбола она далека, но решила поставить наугад, чтобы интереснее было наблюдать за матчами, которые постоянно смотрели дома ее муж и сын. Выбор исхода события происходил очень просто: сын зачитывал матери вывески матчей, которые должны были состояться в тот день, а она выбирала названия команд, которые для нее лучше звучали.

Самый большой выигрыш из букмекерской конторы вынес британский производитель кухонной мебели. Он поставил всего лишь 5 фунтов на коэффициент 200000 и выиграл 1000000. 33-летний болельщик сделал ставку на финальную игру чемпионата Европы 2016 года, в котором встречались Франция и Португалия. Он предсказал не только итоговый счет 
матча, но и автора единственного гола, а также точное время, на котором этот гол будет забит. После того, как ставка сыграла, болельщик даже не знал о своем выигрыше, поскольку просто забыл про нее, потому что делал ставку в спешке перед отчетом в Грецию. С отпуска производитель мебели возвращался уже миллионером.

В заключении работы стоит отметить, что ставки безусловно зависят не только от удачи, но и от многих факторов, которые уже были перечислены в данной работе. И также важно отметить, что делая ставки нужно быть крайне аккуратным в выборе букмекерской конторы, а также уметь правильно управлять банкроллом. Все остальное придет с опытом.

$$
* * *
$$

1. Александров С.Г. Азартные игры как объект мошенничества // Общество и право. - 2005. - № 3 (9). - С. 140142.

2. Сорокин М.А., Александров С.Г. Международный кубок Конфедераций по футболу - 2017: состояние, перспективы, возможности // Актуальные проблемы современной науки: Материалы V Международной научно-практической конференции молодых ученых, аспирантов, магистрантов и студентов. - Краснодар: ККИ РУК, 2017. - С. 182-183.

3. https://smartgambling.ru/novichkam

4. https://stavki-na-sports.com/articles/

5. https://www.1cupis.ru/info/blog

6. https://probukmeker.ru/post

7. https://bukmekerobzor.info/stati

\section{Садыралиев Ж. \\ Проблемы применения статистических инструментов при оценке развития муниципальных образований}

Джалал-Абадский государственный университет имени Б.Осмонова

doi: 10.18411/trnio-09-2021-27

(Кыргызстан, Джалал-Абад)

\section{Аннотация}

На первый взгляд кажется, что с методологической точки зрения вопрос оценки социально-экономического развития органов местного самоуправления (муниципальных структур) не представит много трудностей, проблем. Однако некоторые недостатки в регулировании законодательства в области сочетания управления в органах местного самоуправления в Кыргызстане, особенно в айыл окмоту и городах районного значения, с государственным управлением, требуют особого внимания к организации статистической работы в этих муниципальных структурах, обуславливают рассматривать эти структуры как объекта для специального обзора.

В данной работе предпринята попытка проанализировать некоторые проблемы информационного обеспечения социально-экономического развития данных айыл окмоту и городов районного значения. Автор попытался охарактеризовать процесс сбора (кем) и использование (через кого) муниципальной статистической информации при ведении мониторинга процессов, происходящих в этих муниципальных структурах (MC), при оценке их экономического роста по отраслям, социально-демографического состава населения, уровня их жизни, при определении уровня комплексного обеспечения услугами социальной инфраструктуры. Особенно были отмечены способы коекретного определения и оценки вклада муниципальных образований в социально-экономическое развитие Кыргызской Республики.

Ключевые слова: муниципальные структуры, айыл окмоту, города районного значения, информационные данные, методы организации, оценки сбора статистической информации, система муниципальных индикаторов.

\section{Abstract}

At first glance, it seems that from a methodological point of view, the issue of assessing the socio-economic development of local governments (municipal structures) will not present many 